\title{
A Project Based Learning interuniversity experience in materials science
}

\author{
L. Cabedo*, T. Guraya**, P. Lopez-Crespo***, M. Royo****, J. Gamez-Perez*, M.

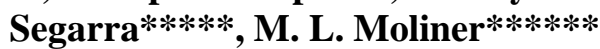

* Departamento de Ingeniería de Sistemas Industriales y Diseño (ESID), Universitat Jaume I, Av. Vicent Sos Baynat, s/n, 12071 Castellón, Spain.

** EUITI, University of the Basque Country, Rafael Moreno Pitxitxi 3, 48013 Bilbao, Spain.

*** Departamento de Ingeniería Civil, de Materiales y Fabricación, University of Málaga,

C/ Dr. Ortiz Ramos, s/n. 29071 Málaga, Spain.

**** Departamento de Ingeniería Mecánica y Construcción, Universitat Jaume I, Av. Vicent Sos Baynat, s/n, 12071 Castellón, Spain.

*****Departamento de Ciencia de los Materiales e Ingeniería Metalúrgica. Facultad de Química. Universitat de Barcelona. C/Martí i Franqués 1, 08028 - Barcelona, España.

****** Departamento de Educación, Av. Vicent Sos Baynat, s/n, 12071 Castellón, Spain.

\begin{abstract}
One of the peculiarities of the present Information and Communication Society is its complexity and changing character. Our education systems, within this new model of society, require a substantial change in their goals and practices. Thus, it is necessary for teachers to adapt to this reality and propose changes on one of the key elements of the curriculum: a methodology in which the student must be the real axis of university education and the teacher a mediator or guide the process. Among the methods that facilitate this transition, the Project Based Learning (PBL) allows learning different basic and/or specific skills, such as interdisciplinary teamwork, personal relationships, ethical commitment or critical thinking. In this paper, we present a proposal for educational innovation based on PBL methodology, conducted with the aim of analyzing its viability in core subjects of materials science engineering in different degrees in Spain. Specifically, it presents a PBL experiment carried out simultaneously by professors of materials science in four Spanish public universities, where the project has been tailored for each curriculum. The results show that this methodology arouses more interest in students than the traditional methodology , while allowing work transversal competences as well as providing a way to evaluate them.
\end{abstract}

Keywords: Project Based Learning (PBL); Interuniversity; Materials Science;

\section{Introduction}

\section{A new educational paradigm}

The information and knowledge society entails a culture sustained by globalization processes involving, among others, the acquisition and assimilation of new knowledge, new ways of seeing the world, the use of new tools and languages, etc., requiring therefore great efforts and skills that facilitate adaptation to this complex and changing scenery (Castells, 1996). The educational systems within the European Higher Education Area require models of teaching and learning to meet the demands of this new paradigm. In this sense, educational institutions must consider three fundamental aspects that facilitate the transition to these social and educational models (Pozo, 2006). First, be aware that the formal environments are no longer the primary, and sometimes not even the main, source of knowledge. Teachers must attend and recognize learning from non-formal and casual spaces. Second, understand that knowledge is multiple and uncertain. The large amount of information that we be accessed raises new skills such as search, evaluate, organize, select and use all this information to be really valid, useful and productive. Finally, it must be considered that learning is a continuous process and extended along life. The world of work demands new requirements; the efficient performance of a profession requires solving tasks in an increasingly higher level and the link between education and job career every day becomes more urgent. 
In addition to these considerations, we must follow the assumptions made by Delors in his report, not just about learning to learn, but learning to do, learning to be and learning to live together (Delors, 1996). This holistic and integrated view of education intends to train citizens that are competent and able to adapt to the social context of change, complexity and uncertainty.

All these ingredients, cooperation, peer learning and skills such as learning to learn or selection and analysis of information, can only be achieved by democratizing the teaching - learning and applying methods of learning that increase activity and participation of the students, who are the real protagonists.

\section{Project Based Learning: basics}

Once described the current educational context we believe that a good tool to address this issue is the Project Based Learning (PBL).

The PBL is a model of learning in which students raise, implement and evaluate projects that have an application in the real world. This method uses problems as a starting point for the acquisition and integration of new knowledge (Barrows, 1986). As other methodologies, it requires a series of well-structured and planned steps set by the teacher.

Moust, Bouhuijs and Schmidt (2007) and Schmidt (1983) proposed seven steps to implement the resolution of the project:

1. Clarification of concepts and terms that appear in the proposal project from the dialogue between group members.

2. First tentative definition of the problem. After steps 3 and 4 this step can be repeated if considered necessary.

3. Analysis of the problem from the contributions of all group members through brainstorming.

4. Development of a systematic summary with several explanations to the analysis of the previous step. Once generated the greatest number of ideas about the problem, the group tries to systematize and organize them, highlighting the possible associations among them.

5. Set up of learning objectives and common decision on aspects of the problem, which are to be investigated and understood.

6. Search for more information, individually.

7. Synthesis of collected information and writing a report on the acquired knowledge.

These phases point the many cognitive processes and competencies required to the students. As already mentioned above, from the organization of work the student develops skills such as problem solving, decision making, teamwork and communication (Michael, 2005). Thus, knowledge is gained while they learn to learn in a progressively independent way as well as they learn to apply that knowledge in solving various problems similar to those they face in the performance of different facets of this work: working in teams under supervision, being progressively autonomous, identifying learning goals, managing time effectively, identifying which aspects of the problem can be ignored or need to explore more deeply and investigating 
on their own, thus directing their own learning. Through this process, they benefit from the participating peers, which provide the necessary contrast to their inquiries and ways of understanding what they are studying (Vizcarro and Juárez, 2009).

One of the strengths that characterize the PBL is its application to different educational levels as well as its versatility to be able to deal with various areas of knowledge. The literature review offers examples of these benefits. Reeves and Laffey (1999) used PBL in an Introduction to Engineering lecture and found an increase in the students' problemsolving skills. However, its implementation in the materials science knowledge area is not very common, being that one of the most traditional engineering subjects and where the introduction of non-traditional teaching methods such as PBL seems to be more difficult. In this sense, Jonassen and Kanna (Jonassen and Khanna, 2011) have analyzed the feasibility of introducing a similar methodology (PBL) in a subject in the field of materials science for mechanical engineers at the University of Missouri and have found that this methodology is very difficult to implement unless this introduction is carried out in curricular way. Thus, their findings show that the introduction of this methodology in only one subject (for this type of degrees) requires great effort from both parties involved: teachers and students, whereas if the methodology is implemented at the level of curriculum for the whole degree, it is much more effective than the traditional learning methodologies.

Despite the predictable difficulty that would involve the implementation of this methodology in material science subjects in engineering degrees, the potential benefits for the students motivated us to start this educational experience, addressed to study the feasibility of using PBL methodology in those subjects in different degrees of Spanish public universities.

The experience is part of a network of educational innovation in materials science formed by teachers from seven Spanish public universities (IdM@ti). Within this network, it was decided to implement the PBL simultaneously on their respective courses, with the aim of analyzing if it was possible to apply it in subjects in this field, regardless the specific degree in which the course is given or any other particular situation of the university. The participating universities were University of the Basque Country-Euskal Herriko Unibertsitatea (hereinafter UPV/EHU), Universitat Jaume I (hereinafter UJI), the University of Barcelona (hereinafter UB) and the University of Málaga (hereinafter UMA).

To the best of our knowledge, this experience is pioneer in Spain, both in the field of knowledge to which it applies, as for its interuniversity character. So in this article we describe the essential elements of our proposal and bring some of the most interesting perceptions of the agents involved, faculty and students.

\section{Methods}

The activity was developed with students from four universities enrolled in different degrees studying subjects related to materials science, all in the field of engineering. This fact brings some aspects worth noting:

- Each engineering degree has a different curriculum and consequently the level of the students' prior knowledge of the subjects is different.

- Objectives and skills to develop in each subject are different. 
- The students are from different school years and this implies different groups regarding the maturity of the students and miscellaneous group circumstances.

- The weight of the ABP activity in the evaluation of the subject is different in each university.

Table 1 summarizes the casuistry.

Table 1. Curriculum of the students and group characteristics.

\begin{tabular}{|c|c|c|c|c|c|}
\hline $\begin{array}{c}\text { University and } \\
\text { degree }\end{array}$ & $\begin{array}{l}\text { Subject } \\
\text { (course) }\end{array}$ & $\begin{array}{l}\text { Size of the } \\
\text { main group }\end{array}$ & $\begin{array}{l}\text { Number of } \\
\text { students in } \\
\text { PBL group. }\end{array}$ & $\begin{array}{c}\text { Number of } \\
\text { PBL } \\
\text { groups. }\end{array}$ & $\begin{array}{c}\text { Weight of } \\
\text { PBL activity } \\
\text { on final grade. }\end{array}$ \\
\hline $\begin{array}{l}\text { UPV-EHU } \\
\text { Industrial } \\
\text { Engineerings } \\
\text { (Ingenierías } \\
\text { Industriales) }\end{array}$ & $\begin{array}{l}\text { Materials } \\
\text { Science } \\
\text { (Ciencia de } \\
\text { materiales) } \\
\left(2^{\circ}\right)\end{array}$ & 60 & 5 & 12 & 30 \\
\hline $\begin{array}{c}\text { UJI } \\
\text { Industrial Design } \\
\text { and Product } \\
\text { Development } \\
\text { (Diseño Industrial } \\
\text { y Desarrollo de } \\
\text { Producto) }\end{array}$ & $\begin{array}{c}\text { Materials II } \\
\text { (Materiales II) } \\
\left(2^{\circ}\right)\end{array}$ & 126 & 5 & 3 & 100 \\
\hline $\begin{array}{c}\text { UB } \\
\text { Materials } \\
\text { Engineerings } \\
\text { (Ingeniería de } \\
\text { Materiales) }\end{array}$ & $\begin{array}{c}\text { Materials } \\
\text { Laboratory } \\
\text { (Laboratorio de } \\
\text { materiales) } \\
\left(3^{\circ}\right)\end{array}$ & 16 & 4 & 4 & 50 \\
\hline $\begin{array}{c}\text { UMA } \\
\text { Industrial Design } \\
\text { and Product } \\
\text { Development } \\
\text { (Diseño Industrial } \\
\text { y Desarrollo de } \\
\text { Producto) }\end{array}$ & $\begin{array}{l}\text { Materials } \\
\text { Science } \\
\text { (Ciencia de } \\
\text { materiales) } \\
\left(2^{\circ}\right)\end{array}$ & 119 & 5 & 11 & 20 \\
\hline
\end{tabular}

As a common element to all projects, the methodology is structured in three sections defined in the documentation provided to the students:

-The project and its objectives are described.

-A closed proposal with minimal requirements within and outside the classroom

-The exact details of the evaluation methodology.

With such common minima each participating university adapted the methodology to their needs and abilities. 
The main focus of the project is to study the design and the redesign of a commercial product, a razor blade. The choice of such a product was based on the following criteria: be affordable for the development of the activity, involving a set of teaching materials of interest and ease to be disassembled and studied. Indeed, it was considered that this product was familiar to the students and easy to access technical and commercial information over the Internet.

While in the UPV/EHU and UB, the whole group of the subject has performed the activity, in the UJI only 15 volunteer students have participated in it. The project was proposed only to a subgroup of high performance students because of the high volume of students enrolled in this course. The selection of them was based on a mixed approach between their average grades in all classes and a motivation letter that was asked to provide to those interested in participating. In the case of UMA, they also decided to implement the PBL activity in a fraction of the total students, as in the UJI, given that there were too many enrolled students. However, it was extended to a larger percentage of students (around 50\% of total enrollment).

The different ways of selection of students to develop the PBL activity show advantages and disadvantages. On the one hand, a selected group does not allow a direct comparison of all results with the whole class, because of the differences in the student's motivation. On the other hand, this method can explore the behavior and performance of students in slightly different contexts. This will allow drawing conclusions such as the suitability of the different ways of selecting students for participating in the PBL activity.

The project proposal varied slightly for each of the four centers in order to adapt it to the different student profiles. Thus, in the case of the UPV / EHU and UMA the statement was that the participants assumed the role of a group of students willing to take part in a contest organized by a major razor blades brand. The purpose was to look for a new design oriented to new market niches, either by consideration of groups of people, environmental considerations, innovative designs, innovative design etc. Once formed the working groups, every member of each group would assume specific tasks, adopting: i) the role of industrial design engineer or ii) role of materials and process engineer. The UMA activity was conducted in coordination with another subject, Industrial Processing. Therefore, special attention to the manufacturing processes used for each component of the blade was given. They also studied in detail the properties of all the materials used.

At the UJI this activity was carried out in coordination with the subject of Conceptual Design, which goes by simultaneously for the first half of the second year. The onset of the activity was proposed as a role playing game (RPG) in which each group was constituted as a design studio, while the teacher was the intermediary between them and the promoter. In this case, the promoter was a foreign razor company that aims to open markets in Spain. Each of the three groups was proposed a project that was slightly different from each other, looking for manufacturing blades intended for a very specific niche market. Thus, one group was asked to design a product for young women, other for sport/leisure which in turn should be fully biodegradable and the third group had to seek maximum profit making a generic product.

In the course of Materials Laboratory at UB, the stated objective was that the students were able to justify the choice of materials in three different commercial blades. As a selection criterion it was used the price-performance ratio evaluated using different experimental tests performed by students. The project was conducted in blended 
learning, combining laboratory sessions and study time of each student. Monitoring the work was carried out by conducting regular control meetings over the duration of the activity, as well as with the presentation of three "deliverables" throughout the activity.

The evaluation methodology was extensively detailed in the documentation provided for the project. A set of criteria to be evaluated in one or more of the activities, such as minutes of meetings, participation in wikis, ICT use, content and presentation videos, reports, etc. were defined In this way it was possible to conduct a competency assessment in agreement with the Bologna process (specific knowledge and transversal skills). However, each teacher had to adapt it to their university systems. With the evaluation of various activities it was possible to draw a note, which had the weight in the final grade indicated in table 1. This percentage is key to the development of the activity, since it has been shown that when the activity has no weight in the final grade the motivation of a large majority of students decreases dramatically (Antepohl, Herzig, 1997).

\section{Results and Discussion}

Acceptance of the project and the involvement of students had different nuances in each university. In the UPV/EHU and in the UMA it has been good; students generally have welcomed with interest the project although the degree of involvement has been uneven. At the UB it has been noticed that as they were senior students and small groups, their involvement was very high and so was the quality of their work. At the UJI, as it was a volunteer project with the most motivated students, their reception was excellent and the students were involved very much. Nevertheless, the average number of hours dedicated to the project exceeded $15 \%$ the plan. It was also noticed a certain degree of competitiveness that we believe may be beneficial since it reflects a personal involvement with the project and desire to excel. A direct correlation between the number of students involved in the PBL activity and the level of involvement and student motivation is observed then. We observed how a great number of students who developed PBL activity increased their interest in the subject. Possibly this behavior comes motivated by greater attention to the student by the teacher. A similar trend between the percentage of PBL activity on the final grade for the course and the level of involvement and student motivation is observed.

The project has eased to find objective ways to evaluate transversal competences as well as its evolution over the semester in the four universities. This process involves a change in evaluation methodology, hard to implement in the field of engineering.

It has been observed that the level reached in the competences of specific knowledge of the subject during the PBL activity had direct positive relationship in the outcome of the evaluation of the same competences by traditional methods (development of a written answer to a question). Therefore it is found that the specific knowledge gained through independent learning is solid and remains after the activity is finished.

In the discussion meetings that were held with students after the experience, the following perceptions were recorded: the students were very receptive and said it was an experience that allowed them to find their way. They noted that, initially, the transfer of responsibilities from the teacher to the students disturbed them, but as they proceeded with the project they developed more autonomous and more independent learning strategies. They agreed that, through the PBL, learning stayed longer. Unlike rote learning, this system provided them with greater retention over time. Despite the 
difficulties encountered with some members of their group, all participants recommend this method of learning to the rest of his classmates. The teachers, on their side, were satisfied with the experience, given the good results obtained; however, the project required an immense amount of work from the teachers and it was concluded that its organization should optimize instrument/evaluation criteria to make the evaluation more objective and less time consuming.

\section{Conclusions}

As a conclusion obtained from this work, the project-based learning arouses interest in the students and helps them to understand their own knowledge of the subject and therefore more successful working with specific skills. Also, this type of approach facilitates working transversal skills and creating and implementing activities and evaluation criteria for these competencies. Specifically, the PBL activity has improved skills in the students such as writing technical documents, search for information, teamwork and presentation of results. As the assessment was continuous, we observed great progresses in the different tests. For example, the quality of their exposition increased during the process. Therefore, this experience has been very positive for teachers but also for students. Some proposals for the future that we think that must be considered are:

- Involve the students in evaluating their peers

- Develop tools to carry out team work effectively and thus reduce the workload of students and teachers

- Improve the efficiency of the evaluation instruments

- Use evidence assessment activity (surveys) for internal use by teachers

Finally, we have demonstrated the feasibility of implementing the methodology of project-based learning with a similar project for different degrees and curricula, which opens prospects for their collaboration. This is the line of work that is intended to continue within the network of educational innovation IdM@ti.

\section{Acknowledgements}

Authors wish to thank the Vicerrectorado de Estudiantes, Ocupación e Innovación Educativa from Universitat Jaume I de Castellón for the financial support throught the Project (PIE 2907/14). Additionally the authors thank the Vicerrectorado de Innovación Docente from Universidad del País Vasco the financial support.

\section{References}

Antepohl, W., Herzig, S. (1997) Problem-based learning supplementing the course of basic phamacology - results and perspectives from two medical schools. NaunynSchmiedeberg's Archives of Pharmacology, 355, R18.

Barrows, H.S. (1986). A Taxonomy of problem-based learning methods. Medical Education, 20(6), 481-486.

Castells, M. (1996). La era de la información. Economía, sociedad y cultura. Vol. 1 México: Siglo XXI. 
Delors, J. (Coord) (1996): La educación encierra un tesoro. Informe a la UNESCO de la Comisión Internacional sobre la educación para el siglo XXI. Madrid, Santillana.

De Miguel, M. (coord.). (2005). Metodologías de enseñanza para el desarrollo de competencias. Orientaciones para el profesorado universitario ante el Espacio Europeo de Educación Superior. Madrid: Alianza.

Jonassen, D. H., S.,Khanna K., Implementing problem based learning in materials science, Proceedings of the 2011 ASEE Annual Conference and Exposition, Vancouver, 2011.

Moust, J.H.C., Bouhuijs, P.A.J., Schmidt, H.G. (2007). El aprendizaje basado en proyectos: Guía del estudiante. Cuenca: Ediciones de la UCLM.

Orozco, J., Guraya, T., Ibarretxe, J., Cabedo, L., Gómez, J., Izquierdo, R., Sales, D., González, D., Lopez-Crespo, P., Segarra, M., Salan, N., Olivella, G., (2012) Interuniversity network for Innovation in Materials Science Teaching, Proceedings of 4th International Materials Education Symposium.

Pawson, E., Fournier, E., Haight, M., Muniz, O., Trafford, J., And Vajoczki, S. 2006. Problem-based learning in geography: Towards a critical assessment of its purposes, benefits and risks. Journal of Geography in Higher Education 30 (1), 103-116.

Pozo, J.I. (2006). La nueva cultura del aprendizaje en la sociedad del conocimiento. In J.I Pozo; N. Scheuer; M. del P. Pérez; M. Mateos; E. Martín y M. de la Cruz. Nuevas formas de pensar la enseñanza y el aprendizaje. Barcelona: Graó.

Reeves, T Y Laffey, J. (1999). Design, assessment, and evaluation of a problem-based learning environment in undergraduate engineering.Higher Education Research and Development, 18(2), 219-232.

Schmidt, H.G. (1983). Problem-based learning: rationale and description. Medical Education, 17, 11-16

Vizcarro, C. Y Juárez, E. (2009) ¿Qué es y cómo funciona el aprendizaje basado en proyectos? La metodología del Aprendizaje Basado en proyectos. Consultado en fecha 20/01/2015. http://www.ub.edu/dikasteia/LIBRO_MURCIA.pdf 